Louisiana State University

LSU Digital Commons

Faculty Publications

Department of Biological Sciences

$1-1-2003$

Matrix heterogeneity and host-parasitoid interactions in space

James T. Cronin

Louisiana State University

Follow this and additional works at: https://digitalcommons.Isu.edu/biosci_pubs

Recommended Citation

Cronin, J. (2003). Matrix heterogeneity and host-parasitoid interactions in space. Ecology, 84 (6),

1506-1516. https://doi.org/10.1890/0012-9658(2003)084[1506:MHAHII]2.0.CO;2

This Article is brought to you for free and open access by the Department of Biological Sciences at LSU Digital Commons. It has been accepted for inclusion in Faculty Publications by an authorized administrator of LSU Digital Commons. For more information, please contact ir@lsu.edu. 


\title{
MATRIX HETEROGENEITY AND HOST-PARASITOID INTERACTIONS IN SPACE
}

\author{
JAMES T. CRONIN ${ }^{1}$ \\ Department of Biological Sciences, 206 Life Sciences Building, Louisiana State University, \\ Baton Rouge, Louisiana 70803-1715 USA
}

\begin{abstract}
In this study, I experimentally examined how the landscape matrix influenced the movement, oviposition behavior, and spatial distribution of Anagrus columbi, a common egg parasitoid of the planthopper Prokelisia crocea. Both species exist among discrete patches of prairie cordgrass (Spartina pectinata), the sole host plant of $P$. crocea. Based on out-planted cordgrass pots bearing host eggs (to assess parasitism) or sticky leaves (traps for adult A. columbi), I found that the distribution of adult female A. columbi and pattern of ovipositions within a cordgrass patch were strongly matrix dependent. Female densities were $59 \%$ lower on the edge than interior of patches embedded in a mudflat matrix, but were evenly distributed within patches embedded in a matrix consisting of either native grasses or the exotic grass smooth brome (Bromus inermis). In contrast, parasitism was higher in the interior than edge for patches in all three matrix types. The lack of correspondence between $A$. columbi density and parasitism was attributed to differences in oviposition behavior: A. columbi parasitized $71 \%$ more hosts per capita in the interior than edge for patches embedded in nonhost grasses, but equal numbers on the edge and interior of patches embedded in mudflat. Matrix-dependent differences in the within-patch distribution and oviposition behavior of $A$. columbi can influence the distribution of parasitism risk and host-parasitoid stability at the patch level.

Matrix composition also affected the pattern of movement through the matrix and the colonization of nearby cordgrass patches. Anagrus columbi females emigrating from a mudflat-embedded patch were captured at very low, but constant, numbers with distance out into the matrix, suggesting that they were reluctant to enter or remain in the mudflat. In contrast, $A$. columbi females entering a nonhost grass matrix had numbers that were high near the patch border and then declined exponentially with distance. These patterns of movement were likely responsible for the very different colonization rates for experimental patches embedded in different matrix types and located $3 \mathrm{~m}$ from a source patch of $A$. columbi. Patches embedded in brome were colonized at a rate that was 3.0 and 5.7 times higher than for patches in native grass or mudflat, respectively. Finally, based on a census of cordgrass patches spanning five generations, A. columbi densities and proportion of patches occupied generally increased with increasing host density, patch isolation, and the proportion of the surrounding matrix that was mudflat. Patch size had no effect on the distribution of $A$. columbi. Overall, these data suggest that cordgrass patches in a nonhost grass matrix, particularly smooth brome, have high connectivity relative to patches in a mudflat matrix. Changes in connectivity due to changes in matrix composition can significantly influence host-parasitoid persistence at the metapopulation level.
\end{abstract}

Key words: Anagrus; connectivity; dispersal; edge effect; egg parasitoid; landscape matrix; metapopulation; patch dynamics; patch occupancy; planthoppers; Spartina; tallgrass prairie.

\section{INTRODUCTION}

Among the numerous theoretical studies of predatorprey dynamics, the consensus is that spatial heterogeneity can significantly affect the temporal dynamics, stability, and spatial distribution of populations (reviewed in Tilman and Kareiva 1997, Hanski 1999, Hassell 2000). The movement of individuals among patches, which is critical to these models, is usually assumed to be affected only by the properties of the patch itself; i.e., patch size, iso-

Manuscript received 26 June 2002; revised 2 October 2002; accepted 16 October 2002. Corresponding Editor (ad hoc): J. A. Rosenheim.

${ }^{1}$ E-mail: jcronin@1su.edu lation, quality, or density of predators or prey (Hanski 1999). This traditional approach ignores the possibility that the matrix within which these patches are embedded may influence dispersal processes and hence, the connectivity among patches (Taylor et al. 1993, Roland et al. 2000, Ricketts 2001). From the vantage point of landscape ecology, treatment of the matrix as homogeneous and unimportant is arguably a major flaw in metapopulation theory (Wiens et al. 1993, Wiens 1997; but see Molainen and Hanski 1998).

For insect herbivores distributed among host-plant patches, the matrix is often heterogeneous, consisting of a complex mosaic of land cover types. Some matrix types may be resistant and favor low rates of interpatch 
movement whereas others may be benign (i.e., have low resistance) and favor high rates of movement. For a single species, the level of matrix resistance may dictate whether the ensemble of subpopulations form a metapopulation or a single patchy population (Harrison and Taylor 1997). For a predator and its prey, differential effects of the matrix on their respective dispersal abilities can profoundly impact regional stability (e.g., Reeve 1988, Comins et al. 1992). Reeve (1988), for example, demonstrated that host-parasitoid interaction persistence can be maintained in the absence of regulatory processes if parasitoid dispersal among patches is greater than that of its host. Whereas a number of studies have identified the effects of matrix composition on the movement patterns of herbivores among host-plant patches (e.g., Kareiva 1985, Jonsen et al. 2000, Roland et al. 2000), no studies have experimentally quantified its effects on interacting species.

In addition to influencing dispersal, matrix composition is likely to also affect the among- and withinpatch distributions of herbivores and their enemies. Occupancy rates and densities are likely to be higher for patches embedded within a low- than a high-resistance matrix (e.g., Kareiva 1985, Jonsen et al. 2000). In the former matrix type, high immigration should promote the rescue effect and the rapid recolonization of vacant patches (Brown and Kodric-Brown 1977, Hanski 1999). Within a patch, some matrix types may inhibit emigration (i.e., the patch edge is impermeable or reflecting; Stamps et al. 1987) and cause organisms to accrue near the patch boundary (Cantrell and Cosner 1999). Other matrix types may foster high patch permeability and the absence of a density edge effect. The study of edge effects has grown in recent years with the recognition that these effects can significantly influence movement patterns, species interactions, and community structure (Fagan et al. 1999). Edge effects have been commonly reported for insect herbivores (e.g., Cappuccino and Root 1992, Roland and Kaupp 1995, Cappuccino and Martin 1997), and in some cases there is evidence that the effects are transmitted to higher trophic levels (e.g., Lovejoy et al. 1984, Bolger et al. 2000). If the edge effect is moderated by the type of matrix, predator-prey interactions may be landscape dependent (see Tscharntke et al. 2002). To advance our understanding of predator-prey interactions at the landscape level, studies are needed that explore how the matrix influences aspects of interpatch movement (e.g., emigration, immigration, patterns of spatial spread) and spatial distributions for both species.

In the tall-grass prairies of the midwestern United States, the planthopper Prokelisia crocea (Van Duzee) (Hemiptera: Delphacidae) is distributed among very discrete patches of its host plant, prairie cordgrass (Spartina pectinata Link [Poaceae]) (Cronin 2003a, b). Within the prairie landscape, cordgrass patches are embedded in one of three basic matrix types: (1) mudflats (sometimes inhabited by saltwort [Salicornia rubra Nels.], (2) a mixture of native grass species (primarily Andropogon scoparius Michx., A. gerardii Vitman, and Agropyron smithii Rydb.), and (3) the exotic grass, smooth brome (Bromus inermis Leyss). Brome is similar in stature and appearance to cordgrass, and both species are taller than most native grasses (Wilson and Belcher 1989). Planthopper adults are 90\% macropterous and quite mobile. The number of immigrants increases with patch area (even single-stem patches are colonized and oviposited within) and is generally unaffected by patch isolation (Cronin 2003b). In a series of field experiments, K. J. Haynes and J. T. Cronin (unpublished manuscript) found that planthopper emigration and immigration rates were highest for patches embedded in nonhost grasses and lowest for patches in mudflat. We also found a matrix-dependent edge effect: planthoppers were generally more abundant at the patch edge relative to the interior for patches in mudflat, but not for patches in nonhost grasses.

In this study, I experimentally examined how the landscape matrix influences the movement and spatial distribution of Anagrus columbi Perkins (Hymenoptera: Mymaridae), a common egg parasitoid of P. crocea (Cronin 2003a). First, I assessed whether an edge effect (in terms of A. columbi density, per capita oviposition rate, and proportion of hosts parasitized) occurred among cordgrass patches and whether those effects were matrix dependent. Second, I estimated $A$. columbi colonization rates of experimental cordgrass patches that were positioned $3 \mathrm{~m}$ away from natural cordgrass patches embedded in each of the three matrix types. Third, patterns of spatial spread through each matrix type were quantified. Fourth, I determined the effects of landscape structure (patch size, isolation, and matrix composition) on A. columbi density and occupancy among patches using five generations of census data. Finally, I addressed how the response to the matrix by $A$. columbi and its host might impact patch connectivity and the spatial and temporal population dynamics of this host-parasitoid interaction.

\section{Methods \\ Life history}

Prokelisia crocea is a monophagous phloem-feeder and dominant herbivore of prairie cordgrass throughout the plant species' range (Holder and Wilson 1992, Cro$\operatorname{nin} 2003 a, b$ ). In North Dakota, planthoppers overwinter as first instar nymphs, reach peak adult densities in early June, and then lay eggs beneath the adaxial surface of cordgrass leaves (Cronin 2003a, $b$ ). A second generation follows, with adults peaking in early August. The most obvious natural enemy of $P$. crocea is A. columbi. Parasitism rates per cordgrass patch range from $0 \%$ to $100 \%$, with an average of $21 \%$ (Cronin 2003a). In general, A. columbi searches for hosts at random within a cordgrass leaf, demonstrates no ability 


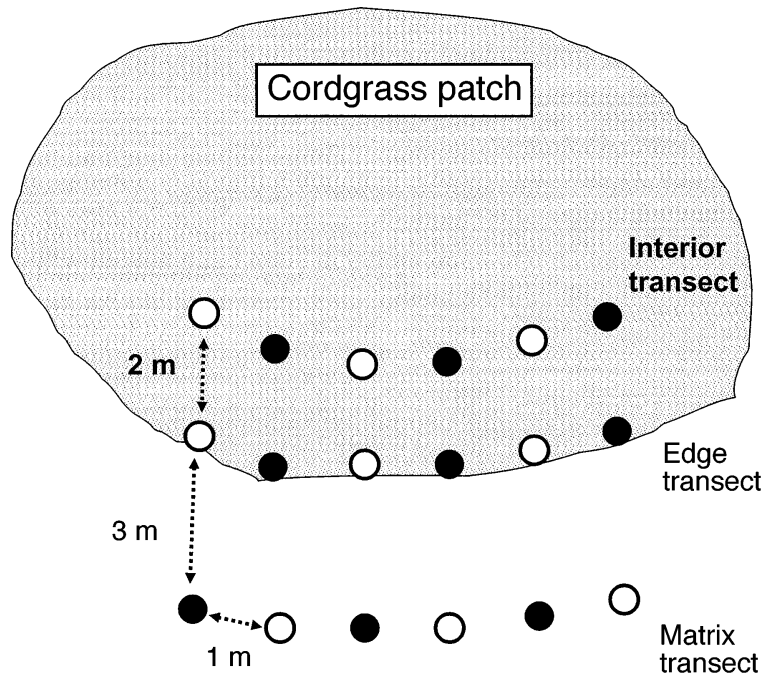

\section{Matrix}

FIG. 1. Diagram of matrix experiment. Potted cordgrass with planthopper eggs (open circles) or Tanglefoot (closed circles) on leaves formed each transect (interior, edge, and matrix). The design was replicated 10 times in each of three matrix types: mudflat, native grasses, or brome.

to avoid superparasitism, and displays a type I functional response over the range of hosts normally found in the field (Cronin 2003a). Although A. columbi has been recorded as a parasitoid of several planthopper species (Krombein et al. 1979), in northeastern North Dakota, it appears to attack only $P$. crocea residing within cordgrass patches (Cronin 2003a).

\section{Matrix experiment}

This experiment was designed to quantify the distribution of $A$. columbi adults and parasitized hosts within cordgrass patches embedded in different matrix types, and to estimate the effects of different matrix types on colonization rates of experimental cordgrass patches. I selected 10 large cordgrass patches (at least $40 \mathrm{~m}^{2}$ in area) that were embedded in each of three matrix types (mudflat, native grass, brome). All patches had a very distinct cordgrass-matrix edge and were separated from each other by a minimum of $50 \mathrm{~m}$. Given the limited dispersal ability of A. columbi (Cronin 2003a), the use of large patches was expected to lessen the importance of patch shape in affecting this parasitoid's movement and distribution within a patch.

Transects of potted cordgrass plants were placed in parallel at $2 \mathrm{~m}$ into the interior, the edge, and $3 \mathrm{~m}$ out into the matrix of each patch (Fig. 1). Within a transect, host pots (pots with host-infested leaves; $n=3$ ) and trap pots (pots with sticky leaves; $n=3$ ) were used to assess $A$. columbi parasitism and density per leaf, respectively. The creation of these pots and their validity in assessing these parasitoid traits are described in Appendix A. Host and trap pots were left in the field for
$7 \mathrm{~d}$ to capture A. columbi and accumulate parasitism. After the pots were collected and returned to the laboratory, I censused the 30 cordgrass patches for stem densities, host densities, and parasitism. I placed a $0.25 \times 0.25 \mathrm{~m}$ sampling frame in three randomly chosen locations along the interior and edge transects, counted the number of cordgrass stems, and collected all of the leaves that were naturally infested with planthopper eggs. Stem densities (on a per square meter basis) at each transect location within a patch were determined from the average number of stems per sampling frame. In the laboratory, the sticky leaves from trap pots were examined with a dissecting microscope and the number of male and female A. columbi counted. After a 5-d incubation period, the leaves from host pots and naturally infested leaves from the census were dissected to determine the number of healthy and parasitized hosts. I note here that at the time of this study, planthoppers were almost entirely in the egg stage. Therefore, eggs laid by resident planthoppers onto potted cordgrass plants did not take place with any measurable frequency.

For each transect location, I used the data obtained from the experimental host pots and trap pots to compute the following transect means (on a per-leaf basis): (1) number of female A. columbi immigrants, (2) proportion of hosts parasitized, and (3) number of hosts parasitized per female A. columbi (mean number of hosts parasitized per leaf/mean number of $A$. columbi captured per leaf). Finally, for each transect separate measures of mean host egg density, number of hosts parasitized, and proportion parasitized were determined for the naturally occurring planthopper-infested leaves.

The effect of matrix type within which a patch was embedded and transect location (interior, edge, or exterior) on A. columbi density, proportion parasitized, and per capita host parasitized were evaluated with separate profile ANOVAs. Here, profile ANOVA is a multivariate test (comparable to a repeated-measures ANOVA; Simms and Burdick 1988) that allows for the three transects associated with each patch to be nonindependent (they share a common environment and are potentially correlated in A. columbi density and parasitism). The responses within each transect (e.g., proportion of hosts parasitized) were the dependent variables and the matrix type was the independent variable. Density and per capita parasitized were ln-transformed and proportion parasitized was arcsine squareroot transformed to achieve normality and homogeneity of variances. To evaluate differences between two matrix types (e.g., brome vs. mudflat), I used the same profile ANOVA model but with only these two matrix types included. Contrasts between the edge and interior (edge effects) and the interior and matrix were evaluated for patches embedded in each matrix type using paired $t$ tests. To ensure that the Type I error rate for each profile ANOVA and contrast (within a matrix) did 
not exceed the nominal rate of 0.05 , Bonferroni sequential corrections were used to assess significance (Sokal and Rohlf 1995).

Finally, the ability of $A$. columbi to successfully disperse from one of the large natural cordgrass patches (10 per matrix type) to an experimental patch located $3 \mathrm{~m}$ into the matrix was obtained from trap-plant captures. Because the 10 cordgrass patches per matrix were relatively isolated from other native cordgrass (minimum of $50 \mathrm{~m}$ ), each likely represented the primary source of A. columbi that colonized the potted cordgrass associated with it. Therefore, my index of colonization rate was the ratio of mean $A$. columbi captures per leaf in the matrix transect and the mean captures per leaf within the source patch ([interior mean + edge mean]/2). Because the distribution of this index could not be normalized (due to a disproportionate number of zeros and a right skew), the effect of matrix composition on the colonization rate was evaluated with a Kruskal-Wallis test (Sokal and Rohlf 1995). MannWhitney $U$ tests (Bonferroni-corrected) were used for all pairwise contrasts.

\section{Movement through the matrix}

To assess how the matrix influences interpatch movement of $A$. columbi, I performed an experiment that quantified the pattern of spatial spread from cordgrass patches embedded in a mudflat or native grass matrix. Large cordgrass patches were selected from the edge of a prairie fragment. Yellow sticky traps $(8 \times 13 \mathrm{~cm}$ Dayglo Saturn yellow index cards coated with Tanglefoot, Tanglefoot Company, Grand Rapids, Michigan) attached to the tops of $0.5-\mathrm{m}$ tall PVC poles were used to capture dispersing A. columbi. The traps were positioned along a transect at $5 \mathrm{~m}$ within the patch, the patch edge, and at 2, 5, 10, 20, and $30 \mathrm{~m}$ away from the patch (and in the opposite direction of other native cordgrass patches). Trap transects were placed in association with six mudflat- and six native grass-bordered patches and were deployed in the field for $2 \mathrm{wk}$, corresponding to the peak activity of $A$. columbi. The number of female $A$. columbi captured in each transect $j$ and trap distance $d, C_{j d}$, was converted to a proportion: $P_{j d}=C_{j d} / N_{j}$; where $N_{j}=$ total number of $A$. columbi captured in transect $j$.

The effect of matrix type (mudflat or native grass) and trap distance on the proportional recaptures (ln $\left.\left[P_{j d}\right]\right)$ was evaluated with a profile ANOVA. As in the previous experiment, traps located at different distances from the same patch could not be considered statistically independent. Tests for differences between matrix types at each trap distance (e.g., mudflat edge vs. native grass edge) were evaluated with separate two-sample $t$ tests (Sokal and Rohlf 1995). The critical value of $\alpha$ for each test was adjusted using a sequential Bonferroni correction to achieve an overall error rate of 0.05 .
Finally, I compared the distribution of $P_{j d}$ for each matrix type with the pattern of spatial spread predicted by a simple diffusion model. Turchin and Thoeny (1993) provided the derivation for the following analytical formula for predicting spatial spread based on cumulative recaptures (see also Okubo 1980): $P_{j d}=$ $A d^{-1 / 2} e^{-d / B}$. Here, $A$ is a scaling parameter and is proportional to the product of the source population and the recapture efficiency. $B$ is a measure of the spatial scale of dispersal and is equal to the square root of the ratio of the diffusion rate and the disappearance rate (death or emigration from the experimental area). An insect population with a large value of $B$ would have a greater dispersal range than one with a smaller $B$. The model above has the linear form, $\ln \left(P_{j d}\right)+1 / 2 \ln (d)$ $=\ln (A)-d / B$, and can be fit using least-squares regression (Sokal and Rohlf 1995).

\section{Landscape effects on spatial distribution}

The effects of landscape structure (patch size, patch isolation, and matrix type) and planthopper egg density on the distribution of $A$. columbi among cordgrass patches was evaluated from census data that spanned five generations (mid-1999 through the end of 2001) and 147 cordgrass patches. The census took place in a single prairie fragment (Site 104), a 65-ha area adjacent to Kelly's Slough National Wildlife Refuge in northeastern North Dakota (47.94184 N, 97.31036 W). Every generation, I ascertained the presence/absence and density of $P$. crocea (eggs) and A. columbi (parasitized hosts) for each cordgrass patch (see Appendix B for details). In addition, each patch was characterized by its size (measured in square meters), isolation from nearest neighbor patches, and composition of the surrounding matrix (Appendix B). Because mudflat was the most different matrix with regard to A. columbi distributions (relative to the two nonhost grass matrices; see Results), I chose to use the proportion of buffer habitat composed of mudflat as my index of matrix composition (see also Moilanen and Hanski 1998). For each generation, I quantified the effect of landscape structure (patch size, patch isolation, and proportion of matrix that is mudflat) and planthopper egg density on two dependent variables: $A$. columbi density and patch occupancy. Least-squares regression was used for the former, and logistic regression for the latter, dependent variable (details are provided in Appendix B).

\section{RESUlts}

\section{Matrix experiment}

On average, A. columbi density (number of females per trap-pot leaf) within a patch was independent of the composition of the surrounding matrix (Table 1, Fig. 2A). However, the distribution of A. columbi within a patch was very strongly matrix dependent, as indicated by the significant matrix $\times$ transect interaction (Table 1). For patches embedded in a mudflat, densities 
TABLE 1. Results from separate profile ANOVAs for the effect of matrix type and transect location within a patch on $\ln$ (parasitoid density), angular-transformed proportion of hosts parasitized, and $\ln$ (per capita parasitized).

\begin{tabular}{|c|c|c|c|c|}
\hline Source of variation & $\mathrm{df}$ & MS & $F$ & $P$ \\
\hline \multicolumn{5}{|l|}{$\begin{array}{l}\text { Parasitoid density } \\
\text { Among patches }\end{array}$} \\
\hline $\begin{array}{l}\text { Matrix } \\
\text { Error }\end{array}$ & $\begin{array}{r}2 \\
27\end{array}$ & $\begin{array}{r}14.43 \\
4.04\end{array}$ & $\begin{array}{l}3.57 \\
3.33\end{array}$ & 0.042 \\
\hline \multicolumn{5}{|l|}{ Within patches } \\
\hline $\begin{array}{l}\text { Transect } \\
\text { Transect } \times \text { matrix } \\
\text { Error }\end{array}$ & $\begin{array}{r}2 \\
4 \\
54\end{array}$ & $\begin{array}{r}19.80 \\
8.01 \\
1.50\end{array}$ & $\begin{array}{r}13.22 \\
5.35\end{array}$ & $\begin{array}{r}<0.001 \dagger \\
0.001 \dagger\end{array}$ \\
\hline \multicolumn{5}{|l|}{$\begin{array}{l}\text { Proportion parasitized } \\
\text { Among patches }\end{array}$} \\
\hline $\begin{array}{l}\text { Matrix } \\
\text { Error }\end{array}$ & $\begin{array}{r}2 \\
27\end{array}$ & $\begin{array}{l}0.09 \\
0.01\end{array}$ & 6.63 & $0.005 \dagger$ \\
\hline \multicolumn{5}{|l|}{ Within patches } \\
\hline $\begin{array}{l}\text { Transect } \\
\text { Transect } \times \text { matrix } \\
\text { Error }\end{array}$ & $\begin{array}{r}2 \\
4 \\
54\end{array}$ & $\begin{array}{l}0.32 \\
0.04 \\
0.01\end{array}$ & $\begin{array}{r}33.21 \\
4.63\end{array}$ & $\begin{array}{r}<0.001 \dagger \\
0.003 \dagger\end{array}$ \\
\hline \multicolumn{5}{|l|}{$\begin{array}{l}\text { Per capita parasitized } \\
\text { Among patches }\end{array}$} \\
\hline $\begin{array}{l}\text { Matrix } \\
\text { Error }\end{array}$ & $\begin{array}{l}2 \\
6\end{array}$ & $\begin{array}{l}6.21 \\
3.82\end{array}$ & 1.63 & 0.273 \\
\hline \multicolumn{5}{|l|}{ Within patches } \\
\hline $\begin{array}{l}\text { Transect } \\
\text { Transect } \times \text { matrix } \\
\text { Error }\end{array}$ & $\begin{array}{r}2 \\
4 \\
12\end{array}$ & $\begin{array}{r}23.24 \\
8.09 \\
1.08\end{array}$ & $\begin{array}{r}21.46 \\
7.47\end{array}$ & $\begin{array}{r}<0.001 \dagger \\
0.003 \dagger\end{array}$ \\
\hline
\end{tabular}

Notes: A Type I error rate for all three ANOVAs combined was maintained at $\alpha=0.05$ by using a sequential Bonferroni correction. A significant $P$ value is indicated with $\dagger$.

declined by $59 \%$ from the interior to the edge (based on the mean proportional difference between transect pairs), a significant density edge effect (Fig. 2A, Appendix C). In the mudflat matrix, A. columbi density was $84 \%$ lower than in the patch interior. In contrast, there was a gradual decline in A. columbi density between the interior and matrix for patches in native grasses (no edge effect evident; Appendix C), and no change in density among transects for the patches in brome (Fig. 2A). Overall, the density distribution of A. columbi adult females among transects within a patch was indistinguishable between patches embedded in mudflat and native grass (as determined from the transect $\times$ matrix interaction term from a profile ANOVA that included only these two matrix types; $\left.F_{2,36}=1.95, P=0.158\right)$ and between native grass and brome $\left(F_{2,36}=3.17, P=0.054\right)$; but the difference was significant between mudflat and brome $\left(F_{2,36}=\right.$ 11.51, $P<0.001)$.

The colonization rate index for experimental cordgrass patches located $3 \mathrm{~m}$ away from a source patch was matrix dependent (Kruskal-Wallis statistic $=6.82$, $\mathrm{df}=2, P=0.030)$. Patches in brome had the highest rate $(0.85 \pm 0.27$; mean $\pm 1 \mathrm{SE})$, followed by native grasses $(0.29 \pm 0.14)$, and finally mudflat $(0.10 \pm$ $0.05)$. Only the rate in brome and mudflat was signif- icantly different (Mann-Whitney $U$ statistic $=53.00$, df $=1, P=0.009$ ).

In contrast to the density distribution of A. columbi, the distribution of parasitism was matrix dependent (Table 1, Fig. 2B). The proportion of hosts parasitized per leaf averaged (all transects combined) $0.17 \pm 0.02$, $0.12 \pm 0.03$, and $0.06 \pm 0.02$ for patches in mudflat, native grass, and brome, respectively. Only the proportion for patches in mudflat and brome was significantly different $\left(F_{1,18}=7.42, P=0.014\right)$. For all three matrix types, parasitism declined significantly from the
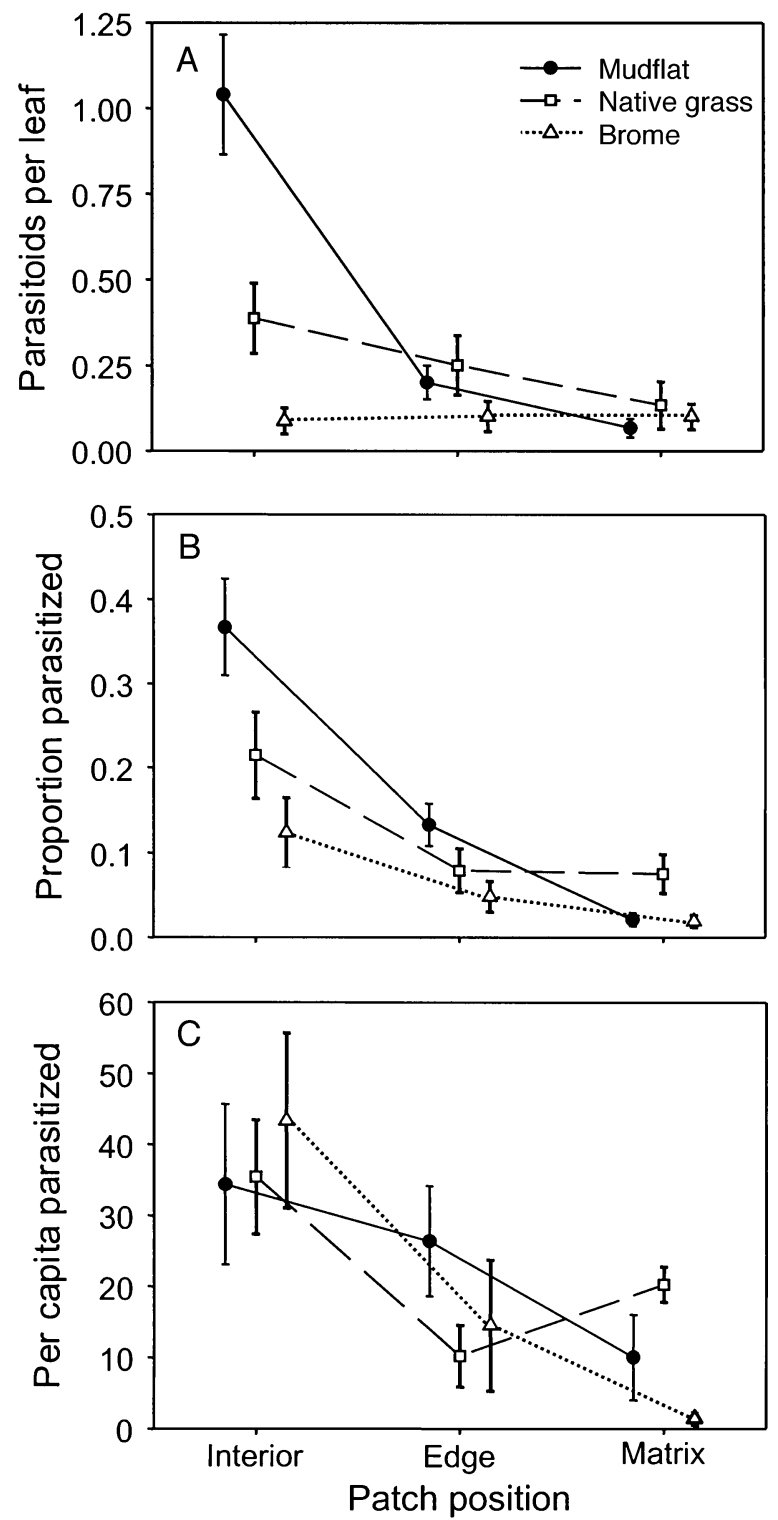

FIG. 2. (A) Parasitoid densities, (B) proportion of hosts parasitized, and (C) per capita number of hosts parasitized for patches embedded in three different matrices (mudflat, a mixture of native grass species, and smooth brome). Patch positions include $2 \mathrm{~m}$ into the interior, the edge, and $3 \mathrm{~m}$ into the matrix. Means \pm 1 SE are reported. 


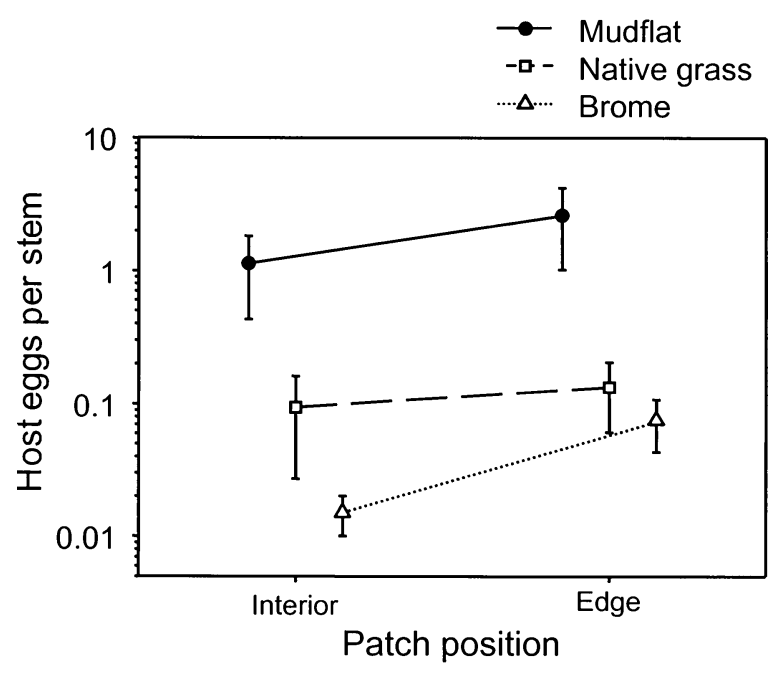

FIG. 3. Natural host-egg densities (mean per stem \pm SE) in relation to the type of matrix within which a patch is embedded and transect location $(2 \mathrm{~m}$ into the patch interior or at the patch edge). Based on a profile ANOVA, $\ln ($ egg densities) were significantly affected by the matrix $\left(F_{2,27}=\right.$ $4.41, P=0.022)$ but not by transect location $\left(F_{1,27}=2.63\right.$, $P=0.117)$. There was no interaction between the matrix and transect location $\left(F_{2,27}=0.98, P=0.388\right)$.

patch interior to $3 \mathrm{~m}$ out into the matrix (Table 1, Fig. 2B). On average, parasitism was $48 \%$ higher on the patch interior than the edge. A significant edge effect in parasitism was found for patches in mudflat and native grass but not for patches in brome (Appendix C). As with A. columbi density, I found that the distribution of parasitism among transects was matrix dependent (significant matrix $\times$ transect interaction; Table 1). Parasitism declined more steeply from the interior to the matrix for mudflat-, than for native grass or brome-embedded patches; however, no significant difference could be found between any two matrix types.

Finally, the per capita hosts parasitized was similar across matrix types, but declined significantly with distance from the patch interior to the matrix (Table 1, Fig. 2C). For all matrix types combined, an average of $44.1 \pm 13.0$ hosts were parasitized per female A. columbi per leaf in the patch interior, $22.4 \pm 6.0$ hosts parasitized at the edge, and $12.8 \pm 4.7$ hosts parasitized in the matrix. Matrix type affected the per capita parasitized only through its interaction with transect location (Table 1). Most notably, a significant edge effect in the per capita parasitized was found for patches embedded in native grass and brome, but not in mudflat (Appendix C). Differences in the distribution of female A. columbi may have explained these patterns. Within a patch (all matrix types combined), the per capita hosts parasitized was negatively correlated with female $A$. columbi density $(R=-0.41, n=60, P=0.020)$.

Differences in the distribution of $A$. columbi females, parasitism and per capita parasitized between the patch interior and edge, could have been influenced by the density of hosts present on naturally occurring cordgrass plants. (Anagrus columbi larvae in naturally occurring hosts were too immature to represent a source of adult parasitoids during the weeklong study; thus, they likely did not play a part in causing the patterns observed in Fig. 2.) Egg densities on natural plants (numbers/stem) were independent of location within a patch, but highly dependent upon matrix type (Fig. 3). Despite these differences, profile ANOVAs (matrix type and transect within a patch as the main effects) performed with and without the density of naturally occurring hosts (In [mean of edge and interior samples]) included as a covariate led to the same conclusions (not reported). Therefore, naturally occurring hosts had no effect on the results reported above.

\section{Movement through the matrix}

The pattern of $A$. columbi captures-with-distance differed fundamentally between a native grass and mudflat matrix, based on the significant matrix $\times$ trap distance interaction term (Fig. 4). In the grass matrix, captures declined gradually from the patch interior to $30 \mathrm{~m}$ out into the matrix. There was no difference in A. columbi captures between the patch interior and edge of grassbordered patches (Fig. 4), corroborating findings in the previous experiment. The linear form of the simple diffusion model provided a significant fit to the combined capture data in the grass matrix: for distances between 2 and $30 \mathrm{~m}$ from the patch edge, $y=-0.04 x-0.96$ $\left(R^{2}=0.32, P<0.001\right)$. The addition of a quadratic term did not improve the model fit. For mudflat-embedded patches, the proportion captured dropped steep-

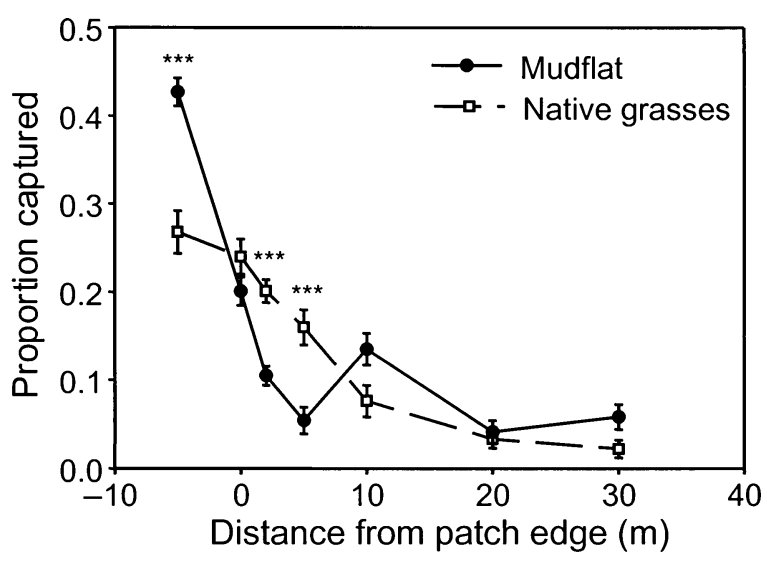

FIG. 4. The proportion of A. columbi captured with respect to distance from the patch edge for two matrices, mudflat and native grass. Means $\pm 1 \mathrm{SE}$ are reported. Based on a profile ANOVA, trap distance and the interaction between trap distance and matrix type $\left(F_{6.49}=68.90, P<0.001\right.$ and $F_{6,49}=14.54, P<0.001$; respectively), but not matrix type $\left(F_{1,10}=4.34, P=0.064\right)$, affected the proportion captured (ln-transformed prior to analysis). Significant differences between matrix types at a given distance are denoted by $* * *$ (in all cases $P<0.001$; based on separate two-sample $t$ tests with a sequential Bonferroni correction of $\alpha$ ). 
TABLE 2. The effect of landscape structure (patch size, isolation, and percentage adjacent matrix that is mudflat) and host density (eggs/stem) on A. columbi density (parasitized hosts/ stem) or whether or not a patch was occupied by A. columbi.

\begin{tabular}{|c|c|c|c|c|c|c|c|c|}
\hline \multirow[b]{3}{*}{ A. columbi } & \multirow{3}{*}{$\begin{array}{l}\text { Genera- } \\
\text { tion }\end{array}$} & \multirow[b]{3}{*}{$n$} & \multirow{2}{*}{\multicolumn{2}{|c|}{ Model statistics }} & \multicolumn{4}{|c|}{ Significance of independent variables } \\
\hline & & & & & \multirow{2}{*}{$\begin{array}{l}\text { Patch } \\
\text { size }\end{array}$} & \multirow[b]{2}{*}{ Isolation } & \multirow[b]{2}{*}{$\%$ Mud } & \multirow[b]{2}{*}{ Hosts } \\
\hline & & & $R^{2 \dagger}$ & $P$ value & & & & \\
\hline \multirow[t]{5}{*}{ Density } & 1999,2 & 25 & 0.593 & $<0.001$ & 0.029 & 0.849 & 0.462 & 0.010 \\
\hline & 2001,1 & 86 & 0.640 & $<\mathbf{0 . 0 0 1}$ & 0.456 & 0.015 & 0.010 & $<\mathbf{0 . 0 0 1}$ \\
\hline & 2000,2 & 86 & 0.725 & $<\mathbf{0 . 0 0 1}$ & 0.233 & 0.003 & $<\mathbf{0 . 0 0 1}$ & $<\mathbf{0 . 0 0 1}$ \\
\hline & 2001,1 & 82 & 0.900 & $<\mathbf{0 . 0 0 1}$ & 0.773 & 0.016 & $<\mathbf{0 . 0 0 1}$ & $<\mathbf{0 . 0 0 1}$ \\
\hline & 2001,2 & $\cdots$ & $\cdots$ & 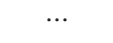 & $\cdots$ & $\cdots$ & $\cdots$ & $\cdots$ \\
\hline \multirow[t]{5}{*}{ Occupancy } & 1999,2 & $\ldots$ & ... & ... & ... & $\ldots$ & ... & $\ldots$ \\
\hline & 2000,1 & 84 & 0.102 & 0.134 & 0.528 & 0.171 & 0.955 & 0.097 \\
\hline & 2000,2 & 89 & 0.430 & $<\mathbf{0 . 0 0 1}$ & 0.819 & 0.008 & 0.042 & 0.009 \\
\hline & 2001,2 & 73 & 0.454 & $<\mathbf{0 . 0 0 1}$ & 0.150 & 0.282 & 0.008 & 0.002 \\
\hline & 2001,2 & 104 & 0.111 & 0.049 & 0.469 & 0.913 & 0.965 & 0.019 \\
\hline
\end{tabular}

Notes: Least-squares regression was used for the continuous variable parasitoid density, and logistic regression was used for patch occupancy frequencies. To control for Type I errors associated with conducting two tests per generation on the same data set, the critical value of $\alpha$ for rejection of the null hypothesis was set at $0.025 . P$ values in bold were deemed statistically significant.

$\dagger$ For logistic regression analyses, McFadden's $\rho^{2}$ is reported instead of $R^{2}$.

ly from the interior to $5 \mathrm{~m}$ out into the matrix, and then remained relatively constant with distance out to $30 \mathrm{~m}$. Because captures did not continue to decline with distance, the slope of the simple diffusion model was not significantly different from zero $(y=0.03 x-2.03$; $\left.R^{2}=0.11, P=0.087\right)$.

\section{Landscape effects on spatial distribution}

The distribution of $A$. columbi among cordgrass patches was well fit by a model that included features of the landscape (patch size, patch isolation, matrix composition) and host egg density. Among the four generations that tests were possible, the model explained an average of $71.5 \pm 6.8 \%$ of the variation in A. columbi distributions among patches (based on model $R^{2}$; Table 2). Clearly the most important factor in the model was host egg density. In all generations, $A$. columbi densities increased significantly with increasing numbers of hosts, and this variable alone explained $59.2 \pm 5.0 \%$ of the total variation in parasitoid densities. The proportion of the matrix that was bare ground (mudflat) and patch isolation had significant effects on A. columbi density (independent of host abundance), explaining $7.4 \pm 3.3 \%$ and $4.9 \pm 3.0 \%$ of the total variation in density, respectively (Table 2). On average, A. columbi densities increased with an increase in the proportion of the matrix that was mudflat and with isolation. Patch size had no effect on $A$. columbi numbers per cordgrass stem.

Patch occupancy frequencies changed substantially over the course of this study. Of the host-infested patches, $100 \%$ was occupied by A. columbi in 1999 (consequently no logistic regression was performed), $86 \%$ in 2000 (generation 1), $88 \%$ in 2000 (generation 2), $74 \%$ in 2001 (generation 1), and 19\% in 2001 (generation 2). The only factor that had a consistent influ- ence on the likelihood that a cordgrass patch was occupied by $A$. columbi (given that hosts were present) was host density (Table 2). For all but one generation (2000, generation $1, P=0.097$ ), the frequency of patches occupied by $A$. columbi increased significantly with increasing host density. Overall, the logistic regression model explained an average of $27 \pm 10 \%$ of the variation in presence/absence of $A$. columbi among cordgrass patches (based on McFadden's $\rho^{2}$ ).

\section{DISCUSSION}

Matrix effects on A. columbi movement and distribution

In the tall-grass prairies of the Great Plains, the landscape matrix appears to have a significant effect on $A$. columbi movement and spatial distribution within and among cordgrass patches. Within mudflat-bordered patches, A. columbi densities were high in the patch interior relative to the patch edge, and were extremely low in the mudflat matrix. In contrast, no edge effect in A. columbi density was evident in matrix composed of nonhost grasses; and for brome-embedded patches, A. columbi densities were just as high $3 \mathrm{~m}$ out in the matrix as in the patch interior. These data suggest that the mudflat edge is not only hard, but possibly repellent (Stamps et al. 1987). Brome edges, and to a lesser extent native grass edges, appear softer and more permeable. Brome is similar in stature and appearance to cordgrass and it is possible that A. columbi does not readily distinguish between these two plant species. The reason that brome has a low resistance to emigrating A. columbi remains unknown.

For patches embedded in all matrix types, parasitism was generally greater on the patch interior than the edge, and this effect was independent of host density. However, the mechanisms generating this edge effect 
differed between cordgrass patches embedded in mudflat and nonhost grass matrices. In mudflat-embedded patches, similar per capita numbers of hosts parasitized between the patch edge and interior (Appendix C), coupled with higher $A$. columbi densities in the interior, likely explained the edge effect (see Fig. 2A). For patches embedded in native grasses or brome, a greater proportion of hosts parasitized in the interior relative to the edge, was likely brought about by an even distribution of $A$. columbi within the patch coupled with a $71 \%$ higher per capita attack rate in the patch interior than the edge. At this point, I do not know the cause for matrix-dependent edge effects in A. columbi oviposition behavior. One possibility is that factors that disrupt oviposition behavior (e.g., predators or wind gusts) may be greater at the patch edge than the interior (e.g., Bowers and Dooley 1993, Burkey 1993). In mudflat edges, those factors may cause A. columbi to disperse to the patch interior, whereas in nonhost grass edges those factors may serve only to reduce successful ovipositions. Another possibility is interference among searching parasitoids (Visser et al. 1999, Hassell 2000). For all matrix types combined, A. columbi density among interior and edge transects was negatively correlated with per capita hosts parasitized. Parasitoid interference, however, could not have accounted for the low per capita attacks $3 \mathrm{~m}$ into the mudflat and native grass matrices where A. columbi densities were also low (Fig. 2B).

Edge effects, such as those found with regard to $A$. columbi densities and parasitism, are evident in a number of other arthropod-predator systems (e.g., McGeoch and Gaston 2000, Tscharntke et al. 2002). The potential population consequences of an edge effect can be manifold (Fagan et al. 1999). In this study system, both the planthopper and A. columbi exhibit a significant density edge effect only in mudflat-embedded patches; however, they have opposite responses to a mudflat edge (this study, see Results; K. J. Haynes and J. T. Cronin, unpublished manuscript). Planthoppers tend to aggregate at the edge, and A. columbi in the interior, of cordgrass patches. By altering the distribution (or ratio) of A. columbi relative to its host, the matrix may indirectly influence a number of factors linked to host-parasitoid stability, including parasitoid functional responses (Kaiser 1983, Abrams 1993), prey outbreaks (Kareiva and Odell 1987), and the distribution of parasitism risk (Hassell et al. 1991, Pacala and Hassell 1991). In a separate study (Cronin 2003a), I found that the distribution of parasitism risk (the coefficient of variation squared in the probability of parasitism among cordgrass leaves) was much more heterogeneous on the patch edge than the interior; increased heterogeneity in parasitism can be theoretically stabilizing (Pacala and Hassell 1991; but see Murdoch and Stewart-Oaten 1989, Gross and Ives 1999).

In addition to its effect on within-patch distributions and behavior of $A$. columbi, the matrix also appears to have a substantial impact on interpatch movement of this parasitoid. In a nonhost grass matrix, A. columbi captures were reasonably well described by a simple diffusion model, a common pattern of redistribution for insect species (Turchin 1998). Movement by A. col$u m b i$ is predominantly at or below the vegetation canopy; traps positioned above the canopy capture few individuals (unpublished data). In contrast, of the few female $A$. columbi that emigrated into a mudflat matrix, captures were distant independent and nondiffusive. This pattern of captures-with-distance from a source would be expected if insects displayed nonrandom directional movements with long step lengths (see Turchin et al. 1991). Linear movement paths in resourcefree or open matrices may be a common pattern among foraging insects (Zalucki and Kitching 1982, Jonsen and Taylor 2000). Under these circumstances, colonization rates of nearby patches embedded in a mudflat matrix likely would be lower than in a nonhost grass matrix where movement is more diffusive, provided that long-range attraction to host sources is similar between matrix types. This is precisely the result observed in my experiment: relative colonization rates of cordgrass patches located $3 \mathrm{~m}$ away from a source patch were more than five times greater in brome and two times greater in native grasses than in mudflats.

To date, few landscape studies have looked beyond simply quantifying turnover rates among patches embedded in different matrices and have attempted to quantify the behavioral bases for matrix effects (but see Crist et al. 1992, Ims 1995, Wiens et al. 1995, 1997, Jonsen and Taylor 2000). The present study is only a first step toward understanding the mechanistic basis for how the matrix influences $A$. columbi emigration (e.g., mudflat edge is less permeable than a brome edge), and interpatch movement (e.g., diffusion in nonhost grasses, something else entirely in mudflats). Behavioral studies at the individual level are needed to further resolve the mechanisms underlying differences in matrix resistance to dispersing A. columbi (see also Gustafson and Gardner 1996).

\section{Anagrus columbi spatial distribution}

It is clear from the five-generation survey of cordgrass patches within a 65-ha prairie fragment that the distribution of A. columbi is tightly linked to the distribution of its host, eggs of $P$. crocea. In all five generations, almost $60 \%$ of the variation in A. columbi abundance (parasitized hosts) was explained by host density. Lei and Hanski (1997) similarly found that abundances of the braconid parasitoid Cotesia melitaearum and its host, the Glanville fritillary Melitaea cinxia, were highly correlated among patches of dry meadow.

Features of the landscape were also important in determining the distribution of A. columbi, but their combined effects accounted for only $\sim 12 \%$ of the variation in abundances among patches. I found that the greater 
the percentage of the nearby matrix that was mudflat, the more dense the local A. columbi population. Because $A$. columbi is less inclined to emigrate from patches in mudflat than in nonhost grasses, it was expected that local populations would build to higher levels in the former than the latter patches. Of equal importance to the matrix in determining A. columbi abundance was patch isolation. In contrast to the findings of many other studies (reviewed in Hanski 1999), isolated cordgrass patches tended to harbor greater $A$. columbi densities. This counterintuitive result is understandable in light of the dispersal and oviposition behavior of A. columbi. I (Cronin 2003a) previously found that the number of $A$. columbi immigrants declined with distance from a source patch. A reduction in number of colonists in an isolated patch, however, was compensated for by a substantial increase in per capita oviposition rates (see also Cronin and Strong 1999). If isolation further reduced the propensity to emigrate, a buildup of $A$. columbi densities that is greater than in nonisolated patches would be expected. Finally, the absence of a patch size effect on A. columbi density corroborates previous experimental studies that found only weak effects of patch size on A. columbi immigration and oviposition behavior (Cronin 2003a). These studies reveal the importance of experimental data in interpreting insect distributional patterns in nature (see also Lei and Camara 1999, Doak 2000a, $b$ ).

\section{Host-parasitoid patch connectivity}

Predator-prey persistence in a spatially subdivided habitat can depend critically upon the relative rates of dispersal of both species (e.g., Reeve 1988, Comins et al. 1992, Holyoak and Lawler 1996). The intervening matrix may therefore greatly affect population dynamics by differentially influencing patch connectivity for a prey (host) species and its predator (parasitoid). In a companion study, K. J. Haynes and J. T. Cronin (unpublished manuscript) experimentally quantified the effects of the matrix on $P$. crocea emigration, immigration, and within-patch distribution. In general, $P$. croce $a$ and $A$. columbi transfer processes were affected in qualitatively the same way by matrix heterogeneity. Mark-release-recapture experiments revealed that patches embedded in mudflat have lower planthopper emigration and immigration rates than comparable patches embedded in brome or native grasses. In the present study, the scarcity of A. columbi at the patch edge and in the mudflat matrix may indicate a low emigration rate, or alternatively, the rapid disappearance of emigrant $A$. columbi from the vicinity of a patch. In contrast, higher $A$. columbi densities in the brome than mudflat matrix may have been due to high emigration rates or a propensity for emigrants to remain near their patch of origin. At the spatial scale of several meters from a source patch, these data suggest that patch connectivity for $P$. crocea and A. columbi is low in a mudflat matrix and high in a brome matrix; native grasses tend to have intermediate connectivity.

In landscapes dominated by native matrix types (native grasses and mudflat), the spatial structure of $P$. crocea is best described as a mainland-island metapopulation with moderately high connectivity (Cronin $2003 b$ ). Because A. columbi appears to track host abundances, it likely exhibits the same population structure, although, A. columbi is more dispersal limited than its host (Cronin 2003a). For landscapes in which brome has displaced native matrix vegetation, the expected increase in patch connectivity (see above) is likely to cause a shift in the spatial structure of these two species from a mainland-island metapopulation to a patchy population (Harrison and Taylor 1997, Thomas and Kunin 1999). Increased patch connectivity due to this change in matrix composition is predicted to lead to high spatial synchrony, low host abundances, and low interaction persistence at a regional scale (Holyoak and Lawler 1996, Harrison and Taylor 1997, Holyoak 2000, Nachman 2001). Exotic plant species such as smooth brome, which are becoming prevalent components of ecosystems worldwide (Drake et al. 1989, D'Antonio and Vitousek 1992), may be playing an important role in affecting the spatial structure and dynamics of populations of native herbivores and their natural enemies.

ACKNOWLEDGMENTS

The completion of this study was made possible by the assistance of the following people: R. Beasler, D. Cronin, F. Dillimuth, J. Geber, K. Haynes, T. Hanel, S. Jorde, C. Rhodes, R. Shefchik, M. Szymanski, A. Widdell, and M. Williams. K. Tompkins of the U.S. Fish and Wildlife Service granted me permission to work at the Kelly's Slough National Wildlife Refuge. I am also grateful to R. Hendersen, H. Johnson, and K. Quanrud for access to their land. K. Haynes, J. Reeve, and two anonymous reviewers provided valuable comments on earlier drafts of this manuscript. This work was supported by the University of North Dakota, ND EPSCoR (EPS9874802), the UND Alumni Foundation, the City of Grand Forks, Louisiana State University, and the National Science Foundation (DEB-9973789).

\section{Literature Cited}

Abrams, P. A. 1993. Why predation rates should not be proportional to predator density. Ecology 74:726-733.

Bolger, D. T., A. V. Suarez, K. R. Crooks, S. A. Morrison, AND T. J. Case. 2000. Arthropods in urban habitat fragments in southern California: area, age, and edge effects. Ecological Applications 10:1230-1248.

Bowers, M. A., and J. L. Dooley, Jr. 1993. Predation hazard and seed removal by small mammals: microhabitat versus patch scale effects. Oecologia 94:247-254.

Brown, J. H., and A. Kodric-Brown. 1977. Turnover rates in insular biogeography: effect of immigration on extinction. Ecology 58:445-449.

Burkey, T. V. 1993. Edge effects in seed and egg predation at two Neotropical rainforest sites. Biological Conservation 66: $139-143$.

Cantrell, R. S., and C. Cosner. 1999. Diffusion models for population dynamics incorporating individual behavior at boundaries: applications to refuge design. Theoretical Population Biology 55:189-207.

Cappuccino, N., and M. A. Martin. 1997. The birch tubemaker Acrobasis betulella in a fragmented habitat: the im- 
portance of patch isolation and edges. Oecologia 110:6976.

Cappuccino, N., and R. B. Root. 1992. The significance of host patch edges to the colonization and development of Corythucha marmorata (Hemiptera: Tingidae). Ecological Entomology 17:109-113.

Comins, H. N., M. P. Hassell, and R. M. May. 1992. The spatial dynamics of host-parasitoid systems. Journal of Animal Ecology 61:735-748.

Crist, T. O., D. S. Guertin, J. A. Weins, and B. T. Milne. 1992. Animal movement in heterogeneous landscapes: an experiment with Eleodes beetles in shortgrass prairie. Functional Ecology 6:536-544.

Cronin, J. T. 2003a. Patch structure, oviposition behavior, and the distribution of parasitism risk. Ecological Monographs 73:283-300.

Cronin, J. T. 2003b. Movement and spatial population structure of a prairie planthopper. Ecology 84:1179-1188.

Cronin, J. T., and D. R. Strong. 1999. Dispersal-dependent oviposition and the aggregation of parasitism. American Naturalist 154:23-36.

D'Antonio, C. M., and P. M. Vitousek. 1992. Biological invasions by exotic grasses, the grass/fire cycle and global change. Annual Review of Ecology and Systematics 23 63-87.

Doak, P. 2000a. The effects of plant dispersion and prey density on parasitism rates in a naturally patchy habitat. Oecologia 122:556-567.

Doak, P. 2000b. Population consequences of restricted dispersal for an insect herbivore in a subdivided habitat. Ecology 81:1828-1841.

Drake, J. A., F. DiCastri, R. H. Groves, F. J. Kruger, H. A. Mooney, M. Rejmanek, and M. H. Williamson. 1989. Biological invasions: a global perspective. Wiley, New York, New York, USA.

Fagan, W. E., R. S. Cantrell, and C. Cosner. 1999. How habitat edges change species interactions. American Naturalist 153: 165-182.

Gross, K., and A. R. Ives. 1999. Inferring host-parasitoid stability from patterns of parasitism among patches. American Naturalist 154:489-496.

Gustafson, E. J., and R. H. Gardner. 1996. The effect of landscape heterogeneity on the probability of patch colonization. Ecology 77:94-107.

Hanski, I. 1999. Metapopulation ecology. Oxford University Press, New York, New York, USA.

Harrison, S., and A. D. Taylor. 1997. Empirical evidence for metapopulation dynamics. Pages 27-42 in I. Hanski and M. E. Gilpin, editors. Metapopulation biology: ecology, genetics, and evolution. Academic Press, San Diego, California, USA.

Hassell, M. P. 2000. The spatial and temporal dynamics of host-parasitoid interactions. Oxford University Press, New York, New York, USA.

Hassell, M. P., R. M. May, S. W. Pacala, and P. L. Chesson. 1991. The persistence of host-parasitoid associations in patchy environments. I. A general criterion. American Naturalist 138:568-583.

Holder, M. W., and S. W. Wilson. 1992. Life history and descriptions of the immature stages of the planthopper Prokelisia crocea (Van Duzee) (Homoptera: Delphacidae) Journal of the New York Entomological Society 100:491497.

Holyoak, M. 2000. Habitat patch arrangement and metapopulation persistence of predators and prey. American Naturalist 156:378-389.

Holyoak, M., and S. P. Lawler. 1996. The role of dispersal in predator-prey metapopulation dynamics. Journal of Animal Ecology 65:640-652.
Ims, R. A. 1995. Movement patterns related to spatial structures. Pages 85-109 in L. Hansson, L. Fahrig, and G. Merriam, editors. Mosaic landscapes and ecological processes. Chapman and Hall, London, UK.

Jonsen, I. D., R. S. Bourchier, and J. Roland. 2000. The influence of matrix habitat on aphthona flea beetle immigration to leafy spurge patches. Oecologia 127:287-294.

Jonsen, I. D., and P. D. Taylor. 2000. Fine-scale movement behaviors of calopterygid damselflies are influenced by landscape structure: an experimental manipulation. Oikos 88:553-562.

Kaiser, H. 1983. Small scale spatial heterogeneity influences predation success in an unexpected way: model experiments on the functional response of predatory mites (Acarina). Oecologia 56:249-256.

Kareiva, P. 1985. Finding and losing host plants by Phyllotreta: patch size and surrounding habitat. Ecology 66: 1809-1816.

Kareiva, P., and G. Odell. 1987. Swarms of predators exhibit "preytaxis" if individual predators use area-restricted search. American Naturalist 130:233-270.

Krombein, K. V., P. D. Hurd, Jr., D. R. Smith, and B. D. Burks. 1979. Catalog of Hymenoptera in America north of Mexico. Smithsonian Institution Press, Washington, D. C., USA.

Lei, G. C., and M. D. Camara. 1999. Behaviour of a specialist parasitoid, Cotesia melitaearum: from individual behaviour to metapopulation processes. Ecological Entomology 24: $59-72$.

Lei, G. C., and I. Hanski. 1997. Metapopulation structure of Cotesia melitaearum, a specialist parasitoid of the butterfly Melitaea cinxia. Oikos 78:91-100.

Lovejoy, T. E., J. M. Rankin, R. O. Bierregaard, Jr., K. S Brown, L. H. Emmons, and M. E. van der Voort. 1984. Ecosystem decay of Amazon forest fragments. Pages 295 325 in M. H. Nitecki, editor. Extinctions. University of Chicago Press, Chicago, Illinois, USA.

McGeoch, M. A., and K. J. Gaston. 2000. Edge effects on the prevalence and mortality factors of Phytomyza ilicis (Diptera, Agromyzidae) in a suburban woodland. Ecology Letters 3:23-29.

Moilanen, A., and I. Hanski. 1998. Metapopulation dynamics: effects of habitat quality and landscape structure. Ecology 79:2503-2515.

Murdoch, W. W., and A. Stewart-Oaten. 1989. Aggregation by parasitoids and predators: effects on equilibrium and stability. American Naturalist 134:288-310.

Nachman, G. 2001. Predator-prey interactions in a nonequilibrium context: the metapopulation approach to modeling "hide-and-seek" dynamics in a spatially explicit tritrophic system. Oikos 94:72-88.

Okubo, A. 1980. Diffusion and ecological problems: mathematical models. Springer-Verlag, Heidelberg, Germany.

Pacala, S. W., and M. P. Hassell. 1991. The persistence of host-parasitoid associations in patchy environments. II. Evaluation of field data. American Naturalist 138:584-605.

Reeve, J. D. 1988. Environmental variability, migration, and persistence in host-parasitoid systems. American Naturalist 132:810-836.

Ricketts, T. H. 2001. The matrix matters: effective isolation in fragmented landscapes. American Naturalist 158:87-99.

Roland, J., and W. J. Kaupp. 1995. Reduced transmission of forest tent caterpillar (Lepidoptera: Lasiocampidae) nuclear polyhedrosis virus at the forest edge. Environmental Entomology 24:1175-1178.

Roland, J., N. Keyghobadi, and S. Fownes. 2000. Alpine Parnassius butterfly dispersal: effects of landscape and population size. Ecology 81:1642-1653.

Simms, E. L., and D. S. Burdick. 1988. Profile analysis of variance as a tool for analyzing correlated responses in experimental ecology. Biometrical Journal 30:229-242. 
Sokal, R. R., and F. J. Rohlf. 1995. Biometry. Third edition. W. H. Freeman, New York, New York, USA.

Stamps, J. A., M. Buechner, and V. V. Krishnan. 1987. The effects of edge permeability and habitat geometry on emigration from patches of habitat. American Naturalist 129: $533-552$.

Taylor, P. D., L. Fahrig, K. Henein, and G. Merriam. 1993. Connectivity is a vital element of landscape structure. Oikos 68:571-573.

Thomas, C. D., and W. E. Kunin. 1999. The spatial structure of populations. Journal of Animal Ecology 68:647-657.

Tilman, D., and P. Kareiva. 1997. Spatial ecology: the role of space in population dynamics and interspecific interactions. Princeton University Press, Princeton, New Jersey, USA.

Tscharntke, T., I. Steffan-Dewenter, A. Kruess, and C. Thies. 2002. Contribution of small habitat fragments to conservation of insect communities of grassland-cropland landscapes. Ecological Applications 12:354-363.

Turchin, P. 1998. Quantitative analysis of movement: measuring and modeling population redistribution in animals and plants. Sinauer Associates, Sunderland, Massachussetts, USA.

Turchin, P., F. J. Odendaal, and M. D. Rausher. 1991. Quantifying insect movement in the field. Environmental Entomology 20:955-963.
Turchin, P., and W. T. Thoeny. 1993. Quantifying dispersal of southern pine beetles with mark-recapture experiments and a diffusion model. Ecological Applications 3:187-198.

Visser, M. E., T. H. Jones, and G. Driessen. 1999. Interference among insect parasitoids: a multi-patch experiment. Journal of Animal Ecology 68:108-120.

Wiens, J. A. 1997. Metapopulation dynamics and landscape ecology. Pages 43-67 in I. A. Hanski and M. E. Gilpin, editors. Metapopulation biology: ecology, genetics, and evolution. Academic Press, San Diego, California, USA.

Wiens, J. A., T. O. Crist, and B. T. Milne. 1993. On quantifying insect movement. Environmental Entomology 22: 709-715.

Wiens, J. A., T. O. Crist, K. A. With, and B. T. Milne. 1995. Fractal patterns of insect movement in microlandscape mosaics. Ecology 76:663-666.

Wiens, J. A., R. L. Schooley, and R. D. Weeks. 1997. Patchy landscapes and animal movements: do beetles percolate? Oikos 78:257-264.

Wilson, S. D., and J. W. Belcher. 1989. Plant and bird communities of native prairie and introduced Eurasian vegetation in Manitoba, Canada. Conservation Biology 3:3944.

Zalucki, M. P., and R. L. Kitching. 1982. The analysis and description of movement in adult Danaus plexippus L. (Lepidoptera: Danainae). Behaviour 80:174-198.

\section{APPENDIX A}

Details on creation of host pots and trap pots for use in estimating A. columbi parasitism and density, respectively, are presented in ESA's Electronic Data Archive: Ecological Archives E084-039-A1.

\section{APPENDIX B}

Census procedure and analyses of A. columbi distributions among cordgrass patches are provided in ESA's Electronic Data Archive: Ecological Archives E084-039-A2.

\section{APPENDIX C}

A table of statistical results for contrasts between the patch interior and edge, and interior and matrix for three A. columbi response variables (density, proportion parasitized, and per capita hosts parasitized) is provided in ESA's Electronic Data Archive: Ecological Archives E084-039-A3. 